\section{Commentary: Conduction disturbances following self-expanding transcatheter aortic valve replacement - mission far from accomplished}

\author{
Derek Serna-Gallegos, MD, ${ }^{a, b}$ and \\ Ibrahim Sultan, MD ${ }^{\mathrm{a}, \mathrm{b}}$
}

Conduction disturbances after transcatheter aortic valve replacement (TAVR) have proven to be a significant problem that need to be overcome to optimize transcatheter aortic valve replacement. Although the technical aspects of TAVR have been significantly more streamlined with improved delivery systems, the rates of conduction disturbances remain unsettlingly high, as quoted in the manuscript of $17.4 \%$ at 30 days and $19.4 \%$ at 12 months in the low-risk self-expanding valve trial. ${ }^{1}$ The effects of new left bundle branch block and need for permanent pacemaker have demonstrated deleterious effects on left ventricular function and progression to heart failure..$^{2-4}$ Rates of left bundle branch block and need for permanent pacemaker have been significantly greater in TAVR than in surgical valve replacement, and as the indications for TAVR continue to expand, the effects of conduction disturbances will become more pronounced as their effects are made more evident in patients with longer life expectancies. ${ }^{5}$ For TAVR to continue to make strides toward becoming a first-line treatment for severe aortic stenosis in younger

From the a Division of Cardiac Surgery, Department of Cardiothoracic Surgery, University of Pittsburgh; and ${ }^{\mathrm{b}}$ Heart and Vascular Institute, University of Pittsburgh Medical Center, Pittsburgh, $\mathrm{Pa}$.

Disclosures: Dr Sultan receives institutional research support from Atricure and Medtronic, which are unrelated to this work. Dr Serna-Gallegos reported no conflicts of interest.

The Journal policy requires editors and reviewers to disclose conflicts of interest and to decline handling or reviewing manuscripts for which they may have a conflict of interest. The editors and reviewers of this article have no conflicts of interest.

Received for publication Aug 27, 2020; revisions received Aug 27, 2020; accepted for publication Aug 28, 2020; available ahead of print Sept 1, 2020.

Address for reprints: Ibrahim Sultan, MD, Division of Cardiac Surgery, Department of Cardiothoracic Surgery, University of Pittsburgh, Center for Thoracic Aortic Disease, Heart and Vascular Institute, University of Pittsburgh Medical Center, 5200 Centre Ave, Suite 715, Pittsburgh, PA 15232 (E-mail: sultani@upmc.edu).

J Thorac Cardiovasc Surg 2022;164:55-6

$0022-5223 / \$ 36.00$

Copyright (C) 2020 by The American Association for Thoracic Surgery

https://doi.org/10.1016/j.jtcvs.2020.08.093

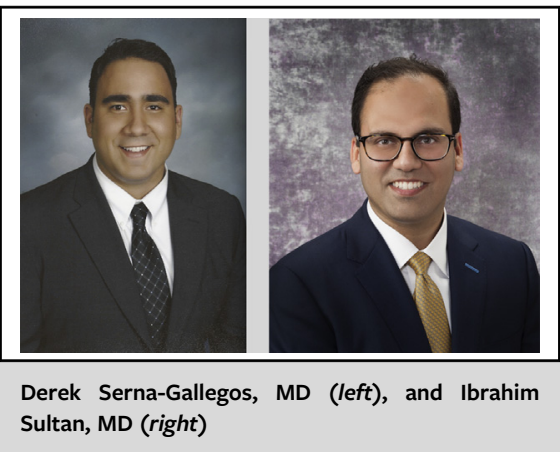

CENTRAL MESSAGE

Preoperative assessment of the length of the membranous septum and intraoperative adjustment of implantation depth may lead to decreased conduction abnormalities after self-expanding TAVR.

and healthier patients, conduction disturbances need to be addressed and decreased.

Chen and colleagues ${ }^{6}$ should be congratulated for their attempt to evaluate and remedy a technical problem with a technical solution. The key to any attempt to solve this issue is that the measurements must be reproducible and able to be obtained with routine imaging that is used for TAVR evaluation. The measurements that the authors study, membranous septum (MS) length in the coronal view and infra-annular MS length from the stretched vessel image, can be obtained from a gated computed tomography angiogram that is used for TAVR evaluation.

The second part of a truly viable solution requires that the image measurements obtained can be applied and executed to the procedure. Even if we can do a great evaluation of the membranous septum and know who is at risk for conduction disturbances and where exactly we want to land the valve, are we actually able to precisely achieve this technical goal in the operating room? The study has not addressed this aspect, as the measurements and results were performed and analyzed retrospectively. The description of the technical aspects the authors employ for the procedure as well as their analysis of the implantation depth, coronal MS length, and coronal membranous septum implantation depth are interesting, but we have yet to be able to deploy the valves with such precision with respect to the membranous septum. The data 
presented and motivation behind the study are valuable and serve as goals to achieve as the precision of valve positioning will improve with time as the delivery systems continue to evolve and the experience of the surgeons and cardiologists performing the procedure grows. As the authors state, the issue at hand is a balance between the risk of valve pop-out with subsequent need to recapture, which risks embolic events or complete valve migration and the risk of conduction disturbances.

\section{References}

1. Popma JJ, Deeb GM, Yakubov SJ, Mumtaz M, Gada H, O’Hair D, et al. Transcatheter aortic-valve replacement with a self-expanding valve in low-risk patients. N Engl J Med. 2019;380:1706-15.
2. Zannad F, Huvelle E, Dickstein K, van Veldhuisen DJ, Stellbrink C, Køber L, et al. Left bundle branch block as a risk factor for progression to heart failure. Eur J Heart Fail. 2007;9:7-14.

3. Zhang ZM, Rautaharju PM, Soliman EZ, Manson JE, Cain ME, Martin LW, et al. Mortality risk associated with bundle branch blocks and related repolarization abnormalities (from the women's health initiative [WHI]). Am J Cardiol. 2012; 110:1489-95.

4. Steinberg JS, Fischer A, Wang P, Schuger C, Daubert J, McNitt S, et al. The clinical implications of cumulative right ventricular pacing in the multicenter automatic defibrillator trial II. J Cardiovasc Electrophysiol. 2005; $16: 359-65$.

5. Kim KM, Shannon F, Paone G, Lall S, Batra S, Boeve T, et al. Evolving trends in aortic valve replacement: a statewide experience. J Card Surg. 2018; 33:424-30.

6. Chen Y-H, Chang H-H, Liao T-W, Leu H-B, Chen I-M, Chen P-L, et al. Membranous septum length predicts conduction disturbances following transcatheter aortic valve replacement. J Thorac Cardiovasc Surg. 2022;164: 42-51.e2. 